\title{
Information Systems Development Methodologies and all that Jazz
}

\author{
Lukasz Michalec and David A Banks \\ University of South Australia, Adelaide, Australia
}

\section{Michalec.Lukasz@postgrads.unisa.edu.au; David.Banks@unisa.edu.au}

\begin{abstract}
This paper explores the relationships between jazz and the development of information systems. Similarities are drawn between music in general and information systems development methodologies and jazz is taken as a specific focus. The idea of music as an information system in its own right is outlined. As systems development methodologies move from formal approaches towards more ad hoc forms, the lessons that can be learned from jazz, such as improvisation and shared meaning, may become increasingly useful.
\end{abstract}

Keywords: Jazz, information system development methodologies, improvisation, socio-technical systems

\section{Introduction}

This paper started life as an individual student assignment for an information systems development methodologies (ISDM) Masters course. In this course a number of approaches are adopted to help students explore different aspects of systems development 'methodology', this term being interpreted as the underlying philosophy that influences the development process. The role of worldviews is taken as a central theme for exploring the underlying philosophies that drive the application of methods or lead to their development. The course is presented from an interpretive perspective and the learning vehicles utilised include debate sessions based around role-played expert witnesses, mapping of methodologies, repertory grids, group discussion sessions and individual conference-style papers (Banks, 2001, 2002). The individual conference-style paper is used to encourage students to develop novel perspectives on the subject matter. This represents a perceived risk for some students but support and considerable encouragement is given in both the selection of the topic and in the initial direction of the paper.

The theme for this paper arose from informal conversations between the second author and Kevin Johnson (University of Cape Town) at the 2003 Informing Science conference. The conversation was triggered by Kevin's ideas of 'music as an information system' and seemed sufficiently intriguing to for the second author to suggest to the ISDM students that this would offer a novel approach to thinking about the philosophical aspects of systems development. This line of thought appealed to one student (the first author of this paper) and the paper presented here is a

Material published as part of this journal, either on-line or in print, is copyrighted by Informing Science. Permission to make digital or paper copy of part or all of these works for personal or classroom use is granted without fee provided that the copies are not made or distributed for profit or commercial advantage AND that copies 1) bear this notice in full and 2) give the full citation on the first page. It is permissible to abstract these works so long as credit is given. To copy in all other cases or to republish or to post on a server or to redistribute to lists requires specific permission from the publisher at Publisher@InformingScience.org modified and extended version of that assignment. 


\section{Methodologies}

WordNet Dictionary defines 'methodology' as:

- the system of methods followed in a particular discipline,

- the branch of philosophy that analyses the principles and procedures of inquiry in a particular discipline.

These definitions are complementary; the first is concerned with tangible aspects of the concept, ie a series of steps, procedures, techniques, tools, and documentation that help to achieve particular goal. The second is about intangible side of methodology, with emphasis upon the underlying philosophy, which makes it different from a method. Jayaratna (1994) defines a methodology as "an explicit way of structuring one's thinking and actions ... A methodology should tell you 'what' steps to take and 'how' to perform those steps but most importantly the reasons 'why' those steps should be taken, in that particular order." Avison and Fitzgerald (1995) note that a significant aspect of a methodology will be based upon "... the 'philosophy', 'viewpoint' - 'bias' if you like - of the people who developed it, for no-one is completely objective". The 'why' will thus represent the personal reasoning of a specific individual methodology developer, derived from their values, beliefs, experience and views of the world. It is this focus on the 'why,' rather than the 'how' that underpins the design and implementation of the ISDM course.

In the IS field a development methodology is typically seen as a guideline, or framework, for systems developers to follow during the development process, usually through clearly defined steps or phases. Currently there are a huge number of information systems development methodologies available, ranging from those that have an engineering derivation through to those that have a socio-technical basis. Several methodologies are combinations or draw inspiration from existing ones creating new composite approaches. All of these methodologies are originally built on their creators' experiences, knowledge and feelings, problem environments and so on, that is, upon their unique worldviews. However, published methodologies are used in practice by people who may only have access to the 'what' and 'how' aspects, without any clear insight to the 'why'. This leads to an interpretive process where the explicit elements of a methodology (ie essentially the step-by-step 'method' aspect) are interpreted within the worldview of another developer and probably within a different environment. The ISDM course attempts to identify some of the 'why' aspects of development methodologies by looking at the biographies of the original developer, their awards, publications, areas of interest and so on to try to build an understanding of the more tacit elements of original developers worldview.

The music domain has a number of parallels with the systems development domain in terms of the method and methodology issue. The inspiration ('why') that drives a composer may not be evident from the musical score (the 'what' and 'how') in the same way the explicit method ('how') of a systems development approach may not express the thinking and motivation ('why') of the original developer. Music, like methodologies, may be highly structured and formal with clearly declared steps and tools (or instruments), or may be more conceptual, fluid and dynamic and constructed in real-time in harmony with the prevailing environment. The aim of music may be to demonstrate technical expertise in playing or in providing a good experience for players and audience. If we look specifically at jazz, Bushie (2003) considers that such music is not simply Art or Music, but primarily a way of life. The deeper, emotional, personal (worldview) aspects are something that cannot be easily learnt from a book; it is something that can be understood only by experiencing it. Bushie further suggests that jazz is not a 'method, algorithm or an idea' but it is something more, perhaps more akin to a philosophy. As with systems development, jazz is not homogenous; there is more than one methodology. The number of jazz methodologies is as many as there are styles in that music. The underlying methodology of classical jazz will be dif- 
ferent from bebop or ragtime. Similarly the underlying philosophy behind systems development methodologies may focus upon producing an engineered artefact, solving a root problem or providing a better working environment for the end users.

Interpretation of jazz by the audience ('users') depends to some extent on the level of 'expertise' of the listeners. Beginners will perceive jazz in more general systemic way, as a broad experience that may be difficult to articulate. As their understanding of the music increases, the level of understanding and appreciation will also grow, thus the interpretation will start changing from a broad feeling towards recognition of the more discrete elements and of the interplay between those elements. Santoro (1994) identifies the demands on the listener as they develop an interpretation and understanding of the music, noting that '.. good listeners have to be willing to stretch and bend and learn and be willing to discard, however provisionally, what they think they know in order to be able to understand afresh. In other words to become a little more like the artist they're listening to.' This active engagement with the product and process accompanied by a willingness to adopt new thinking and discard some old views may have some value in the information systems development process. As end users move from an initial naïve view towards a broader understanding of the system and its wider functions they may need to be helped to revise their original thinking so that they can incorporate new possibilities and possibly reject existing ones. Similarly the developer needs to recognise the benefits of participatory engagement with the users so that they too can gain deeper insight to the required product and user-oriented view of the process.

A sense of passion and of sharing ideas and themes combined with continual adjustment and innovation may be as important for systems development as it is to the performance of jazz. Some information systems development methodologies such as Mumfords' ETHICS (Effective Technical and Human Implementation of Computer-Based Systems) do stress the issues of participative design and the effects caused by change. Mumford (1983) urges that conflicts need to be surfaced and dealt with in such a way that the needs of all participants are acknowledged and satisfied. This leads to an ISDM that has a strong underlying philosophy that recognises and values all participants within the context of a socio technical system and appreciates the need for change and growth. Such an approach is as different to an engineering view as jazz is to a fair organ.

\section{Information System and Music}

Information Systems is a multidisciplinary field that both draws up and contributes to the bodies of knowledge and praxis of a broad range of disciplines in both arts and sciences. At one end of the spectrum lies hard engineering, at the other lies business and management, with links to sociology, psychology, architecture and so on. The 'hard' (Information Technology) end of the connection supplies the engineering skills to design and build technological infrastructures that support the needs and aspirations of the softer business and management (Information Systems) areas. Understanding of the interactions that take place within socio-technical systems draw upon such areas psychology, sociology and ethics. This broad scope of the information systems field has synergies with both arts and sciences, and the adoption of a music-oriented perspective of information systems offers the potential for new insights.

Johnson (personal email correspondence, 28-08-2003) views music as an information system with a song consisting of several informational 'parts', these being the words or melody lines. Moreover, it can include several 'layers' of worlds (for example lead singer and for backing singers etc) as well as different melody lines (different scores for different instruments). All these inputs need to be brought together (processed) correctly in order to achieve a desired output. The music system is influenced by the prevailing environment, sounding different if enacted in a hall or at an open-air venue. Feedback links the musicians and the audience and this feedback may dampen or reinforce the overall performance. Technological issues such as the choice and arrangement of 
instruments, levels and quality of any electronic amplification, acoustic response of the venue and so on also influence the overall ambience. In the case of many classical music performances where there are strict rules in force and there are hierarchies and clearer separation between the orchestra and the audience, the influence from external factors will be limited (Waltzer \& Salcher 2003). In jazz the elements of improvisation, jamming, dynamic involvement of the players and the audience are very important. Much of the recent literature in the systems development field also recognizes the significance of ad hoc actions, iteration, adjustment and active audience (end user) involvement in the whole process.

Music can be described as 'an artistic form of auditory communication incorporating instrumental or vocal tones in a structured and continuous manner' (WordNet Dictionary, 2003). There is enormous diversity in music styles and for the purpose of this paper the focus will be specifically upon Jazz music. Other forms of music lend themselves to analogical comparisons with information systems development methodologies, for example a large orchestral piece with its clear structure, adherence to specification, hierarchical structures and so on can be seen in the same light as very formal approaches such as Structure Systems and Analysis Design Methodology (SSADM), Projects in Controlled Environments (PRINCE) and so on. Our focus here is upon the softer systems development methodologies, for example Soft Systems Methodology (SSM) and Multiview, and jazz offers a more useful musical basis for exploration of this area.

At a superficial level the comparison of jazz music and information systems may suggest that they have little in common. However, when we examine both concepts carefully, several similarities can be distinguished. In both, jazz music and information systems worldview of the performer and the developer respectively plays a significant role. The worldview, or weltanschauung, is the unquestioned image or model of the world that makes a particular human activity system meaningful (Checkland, 1999). It is a portfolio of personal critical beliefs and assumptions which are created by individuals, based on their knowledge, experiences and beliefs that influence the manner in which an individual views and acts upon specific circumstances.

In the information systems domain it can be argued that the worldviews of the various actors involved in the process of systems development impact upon the development process. Even with the same given method (ie, recipe, or set of instructions), individuals will approach the process with differing underlying perspectives. Thus it is possible to develop a system form a strongly engineering viewpoint with little regard for the eventual users, the key focus being issues of time, cost and quality in accordance with a specification declared at the start of the process. Bell and Wood-Harper (1998) characterise developers with this orientation as 'technocratic analysts'. On the other hand, the same basic method may be used but with a strong awareness of the social and ethical impacts of the system on the eventual, and of the way that the process itself changes the socio-technical nature of the development environment. This would be classed as essentially a 'soft' perspective or the 'facilitator/teacher analyst' (Bell \& Wood-Harper, 1988). Thus a given system may have a specification and be developed and implemented in accordance with a stated methodology, but the actual execution will be influenced by the worldviews of those engaged in the development process.

Similarly in jazz, the performer's worldview will strongly impact upon the translation of the notes on the page into a performed activity. The soft approach is when the jazz is focused on the audience, with primary intention to create good relaxing, friendly atmosphere and providing entertainment for listeners. 'Soft jazz' is more simplistic than the hard version. On the other hand, in a hard approach the performers are reaching boundaries of their technical skills, which are in many cases appreciated only by narrow group of expert or skilled instrumentalists.

The complexity and dynamism of information systems and jazz music influence the approach to problem solving. Problems and issues in the development of socio-technical information systems 
are never the same, even when the systems specifications appear to be quite similar. Different technology architectures, different organisational structures and cultures and, above all, different arrangements of people will lead to each system having specific attributes and combinations of those attributes. This is not to say that no learning can take place or that every development action is totally; clearly there are themes that run through a given range of systems development events. However, we suggest that the use of a single relatively fixed 'arrangement' or tune for a variety of potentially very different situations may not be as effective as a dynamically adaptive approach.

A key concept of jazz music is constant change, improvement, exemplified by Louis Armstrong's advice to "never play the same song twice." In normal everyday life the performers are influenced by a number of factors including music, personal relationships and broader issues in everyday life and the world in general. All these aspects lead to continuous change in a person, and so will have an impact on the way that they approach, interpret and perform their music, possibly even while in the action of performing that music. The same argument can reasonably be applied to systems developers and to the way that they approach development processes.

\section{Jazz lessons for systems developers}

What really singles out jazz from other types of music is improvisation and jamming and these offer potentially useful views of IS development. Both jazz and systems development deal with problems that are unstructured, ambiguous, dynamic, socio-technical, innovative and unique. Both find and develop structures and solutions that did not exist before. Both can rely, to differing degrees, on 'improvisation', from Latin word 'improvisus', which means: not seen ahead of time (Barret, 1998). Both require a measure of creativity, insight and understanding of their respective audiences. Kao (1997) captures the process of 'jamming' in jazz, which is described as '... to take a theme, a question, a notation, a whim, an idea, pass it around, break it up, put it together, turn it over, run it backwards, fly with it as far as possible, out of sight, never retreating... but yes, here it comes homing in, changed, new, the essence, like nothing ever before.' This suggests a more creative than strictly scientific approach, and one that accepts errors as part of the process of growth and development. There is also an underlying issue of free-wheeling 'fun', a notion that may not sit too comfortably with individuals who prefer to follow a strict set of guidelines, even though evidence suggests that slavish adherence to systems development methodologies often ends with a less that successful outcome (Wastel, 1996). Flood (1995) is one of the few writers who specifically incorporate the idea that problem solving and systems development should be fun if circumstances permit. In the description of his Total Systems Intervention (TSI) approach he parallels improvisation when he describes the TSI process as starting with creativity and then responding dynamically and iteratively to the changes that arise from implementation of earlier ideas.

Other qualities of jazz that could be important for IS development include:

- Anticipation of the future and of change in the present. The ad hoc nature of improvised jazz means that all those involved have to be sensitive to subtle changes in direction and adjust their own performances in line with these changes. Developers of information systems must see the directions in which not only the technology is moving, but, even more importantly, the directions of people and organization for whom the system is being created. This understanding is vital in the field of IS. Lack of understanding of the implications of ongoing change, particularly in the case of long development periods may lead to failure to meet the requirements of the project.

- Continual adjustment to the environment. It is not unusual for large IS projects to last for a number of years and in this time the environment will change. Jazz has many forms and 
these have typically emerged from specific environments over a period of time. In the IS field technology will change, user perceptions will change and organisational needs will change in a turbulent world. These changes need to be seen as opportunities and as sources of inspiration rather than as constraints. Methodologies that incorporate sensitivity to change and appropriate mechanisms for dealing with that change would appear to have a stronger future than those that are more rigid.

- Constant negotiation is closely associated with communication in general, but it has deeper meaning. It indicates not only the informing role of communication, but it underlines the often tacit and emotional user involvement in the process.

- Permanent fight with routine, permanent search for new forms. That is directly connected with the attitude to problem solving - if there are no identical problems, then there are no identical solutions. Thus there is no 'ideal' information system any more than there is an 'ideal' piece of music. The unique and changing dynamics of environment, performers and technology require continual re-appraisal and critical thinking. Retention of rigid or formalized methodologies can lead to a tendency to simply pass the blame for any failures to meet audience expectation on the methodology. The use of methodology as a fetish or totem that can be blamed for wider failures needs to be avoided (Wastel, 1996)

- Shared views and valuing the skills of co-performers. Observation of a jazz band that is performing well reveals considerable eye contact, exchange of smiles, and willingness to allow performers to periodically take centre stage to demonstrate their particular skills. Although formal leadership may exist there is a willingness to follow any member of the band if a new and interesting avenue emerges during the performance. It is interesting to note that jazz bands typically invite musicians from the audience to join them and the shared understanding of the theory of music and the specific genre allow good performances to occur. This continuous informal communication, dynamic consensual negotiation and sharing of leadership at appropriate instants may be a useful model for systems developers to consider.

\section{Success and Failure}

We now turn our attention to issues of success and failure in both cases. Information systems development attracts considerable criticism in terms of its ability to deliver a system that meets the needs of the business and the users. Many systems fail to be delivered on time, or to meet cost, quality, and/or functionality criteria even when highly formal methods are used. In fact this may not be a fair criticism of systems development as such, given the complex and changing environment within which systems are developed and also upon interpretations of the emotive terms 'success' and 'failure'. Lyytinen and Hirschheim (1987) identify a number of types of failure, including correspondence, process, interaction and expectation failure. Correspondence refers to failure to meet pre-specified objectives, and process and interaction relate, respectively, to not meeting the time/cost constraints and non-adoption of the system by the eventual users. Expectation failure is defined as the 'inability of an IS to meet a specific stakeholder group's expectations'. Saeur (1993) is critical of the expectation failure category on three points; firstly that some expectations are more reasonable than others; secondly, that expectation failure ignores intention, and thirdly, that some stakeholders have greater capacities than others. Despite this criticism he makes the comment that the expectation failure does have the virtue that it makes explicit the idea that failure is relative to interests which may reasonably differ among stakeholder groups. This theme could probably be further developed to bring in the emotive issues that may moderate a perceived failure back to qualified success. The judgement of 'success' and 'failure' depends very 
much on the worldview of the observer making the judgement, but there is considerable evidence that information systems development delivers relatively few totally successful outcomes.

Does jazz 'fail'? One answer is presented by Pat Metheny, who comments that "There is more bad music in jazz than any other form. Maybe that's because the audience doesn't really know what's happening." However, even a performance that may have some flaws can still achieve a desirable outcome if there is give and take between audience and performers. Another view is that one false keystroke may be the start of the discovery of something new, thus the final outcome may be positive even though part of the process deviated from the original path. Improvisation only works if the audience is willing to tolerate errors and see beyond the purely technical aspects of the performance. Of course, too many technical errors or improvisation that exceeds the understanding of the audience would probably be classed as a 'failure'. One area for investigation for systems developers may be to consider how it may be possible to develop a relationship between all parties involved in the process such that failures can be acknowledged and recognised to be an opportunity as well as a problem.

Avison and Fitzgerald (2003) suggest that we are moving away from an era of formal methodologies into a more ad hoc development environment, characterized by trial and error and reliant on the skills of those involved in the process. The advent of 'lightweight' or agile systems development methodologies, Rapid Applications Development (RAD), Object Oriented approaches, with the re-use of themes, all suggest a movement from rigid, formal approaches to a more empathetic approach that recognizes the value of all parties involved in the development 'performance'. This seems to be quite closely allied with the idea of improvisation and perhaps looking at systems development through a 'jazz' lens may offer some useful insights. The description by Kao (1997) of 'jamming', given earlier in the paper is worth re-stating here - “... to take a theme, a question, a notation, a whim, an idea, pass it around, break it up, put it together, turn it over, run it backwards, fly with it as far as possible, out of sight, never retreating... but yes, here it comes homing in, changed, new, the essence, like nothing ever before."

The latter approach involves risk, errors, breaking new ground. Kamoche and Cunha (2001), exploring the relationship between jazz improvisation and product innovation, suggest that managers can translate improvisation in actionable ideas, including rotating leadership and controlled freedom. Both of these ideas raise some fascinating opportunities for experimentation in systems development environments. There are, of course, difficulties with such open-ended, iterative and participative approaches. For example pre-determination of the number of iterations in a creative process may be highly problematic, in which case the prediction of final costs may be almost impossible. However, early iterations and on-going participative re-design may avoid costly re-work later in the process.

\section{Conclusion}

This paper has explored some of the issues that relate information systems development and jazz. The roles of interpretation and the worldviews of individuals have been identified as significant aspects of developing an understanding of these areas. The idea of an underlying 'philosophy' from which methods and frameworks arise has been briefly examined in the domains of systems development, music and, to a lesser extent, education. Some of the language of jazz has been used to provide a vehicle for exploration of information systems development, on the basis that there are some shared philosophies between them.

We acknowledge that there are differences between jazz improvisation and information systems development methodologies and between end users of information systems and a transient audience in a jazz club. Our concern here has been that in a changing, information-hungry and information-dependant world we may need to consider new approaches to the development of ubiqui- 
Information Systems Development Methodologies

tous systems that include us all as their end users or audiences. We suggest that thinking about jazz in the context of such systems can provide a useful metaphor, or 'lens', that can be constructively brought to bear upon the area of information systems development methodologies.

\section{Acknowledgement}

Our thanks go to Kevin Johnson for his supportive and encouraging emails to the first author.

\section{References}

Anderson, J. (2003, Jan 13). Definition of 'Worldview'. Retrieved 14 September 2003 from http://groups.yahoo.com/group/vantil-applied/message/895

Avison, G., \& Fitzgerald, D. E. (1995). Information systems development: Methodologies, techniques and tools $\left(2^{\text {nd }}\right.$ ed.). McGraw Hill.

Avison, G., \& Fitzgerald, D. E. (2003). Information systems development: Methodologies, techniques and tools ( $3^{\text {rd }}$ ed.). McGraw Hill

Banks D A. (2001). A multi perspective approach to learning about information systems development methodologies. Systems in Management $7^{\text {th }}$ Annual Australian and New Zealand Systems Conference (ANZSYS), Perth, November 2001.

Banks D A. (2002). Developing an argumentative approach to teaching information systems development methodologies. Information Resources Management Association (IRMA) conference, Seattle, May 2002.

Barrett, F. J. (1998). Managing and improvising - Lessons from jazz. Career Development International, 3 (7), 283-286.

Bell, S., \& Wood-Harper, T. (1998). Rapid information systems development: Systems analysis in an imperfect world. McGraw-Hill.

Bush, L. R. (1991). A handbook for Christian philosophy. Grand Rapids, MI: Zondervan Publishing House.

Bushie, C. (2003). Understanding of Jazz Music. Retrieved 18 September 2003 from http://ellerbruch.mnu.edu/classes/cs255wO3/cs255students/ebushie/P6/tutorial.htrnl

Checkland, P. B. (1999). Systems thinking, systems practice. Wiley.

Flood, R. L. (1995). Solving problem solving. Wiley.

Jayaratna, N. (1994). Understanding and evaluating methodologies: NIMSAD, A systems framework. McGraw Hill.

Kamoche, K., \& Cuhna, H. P. (2001). Minimal structures: From jazz improvisation to product innovation. Organisation Studies, 22 (5).

Kao, J. (1997). Jamming - Art and discipline of corporate creativity. New York, NY: HarperCollins.

Lyytinen, K. \& Hirschheim, R. (1987). Information systems failures: A survey and classification of the empirical literature. Oxford Surveys in Information Technology, 4.

Metheney, P. (n.d.) Jazz Quotes Database. Retrieved 23 January, 2004, from http://www.newtojazz.com/quotes.asp?section=useful\&person=Pat\%20Metheney

Mumford, E. (1983). Designing human systems. Manchester, UK: Manchester Business School.

Santoro, G. (1994). Dancing in your head. New York, NY: Oxford University Press.

Sauer, C. (1993). Why information systems fail: A case study approach. Alfred Waller, Henley on Thames.

Waltzer, N., \& Salcher, A. (2003). Management by jazz - Creating innovation from the principles of chaos and order. Industrial and Commercial Training, 35 (2), 67-69. 
Wastell, D. G. (1996). The fetish of technique: Methodology as a social defence. Information Systems Jour nal, 6, 25-40.

WordNet Dictionary. (2003). Methodology. Retrieved 18 September 2003from http://www.hyperdictionary.com/dictionary/methodology

WordNet Dictionary. (2003). Music. Retrieved 18 September 2003 from http://www.hyperdictionary.com/computing/music

\section{Biographies}

Lukasz Michalec is currently studying for a Master of Management Information Systems at the University of South Australia. After graduating with a BA in Business Administration from Nowy Sacz School of Business at the National Louis University, Poland, he decided to take up the personal and cultural challenge of further studies in Australia.

David A Banks is a lecturer in Information Systems at the University of South Australia, responsible for Information Systems Development Methodologies and Collaborative Information Systems at masters level. His learning support approach is essentially interpretive and he uses Audience Response Systems to support some learning activities. He has taught in the UK, Hong Kong, Singapore and New Zealand. 